\title{
ORIGINAL
}

\section{Benefit-to-risk balance of bronchoalveolar lavage in the critically ill. A prospective, multicenter cohort study}

Toufik Kamel' ${ }^{1}$, Julie Helms², Ralf Janssen-Langenstein ${ }^{3}$, Achille Kouatchet ${ }^{4}$, Antoine Guillon ${ }^{5}$, Jeremy Bourenne ${ }^{6}$, Damien Contou ${ }^{7}$, Christophe Guervilly,9, Rémi Coudroy ${ }^{10,11}$, Marie Anne Hoppe ${ }^{12}$, Jean Baptiste Lascarrou ${ }^{13}$, Jean Pierre Quenot ${ }^{14}$, Gwenhaël Colin ${ }^{15}$, Paris Meng ${ }^{16}$, Jérôme Roustan ${ }^{17}$, Christophe $\mathrm{Cracco}^{18}$, Mai-Anh Nay ${ }^{1}$, Thierry Boulain ${ }^{1 *}$ (D) and Clinical Research in Intensive Care Sepsis Group (CRICS-TRIGGERSEP)

(c) 2019 Springer-Verlag GmbH Germany, part of Springer Nature

\begin{abstract}
Purpose: To assess the benefit-to-risk balance of bronchoalveolar lavage (BAL) in intensive care unit (ICU) patients.

Methods: In 16 ICUs, we prospectively collected adverse events during or within $24 \mathrm{~h}$ after BAL and assessed the BAL input for decision making in consecutive adult patients. The occurrence of a clinical adverse event at least of grade 3, i.e., sufficiently severe to need therapeutic action(s), including modification(s) in respiratory support, defined poor BAL tolerance. The BAL input for decision making was declared satisfactory if it allowed to interrupt or initiate one or several treatments.

Results: We included 483 BAL in 483 patients [age 63 years (interquartile range (IQR) 53-72); female gender: 162 (33.5\%); simplified acute physiology score II: 48 (IQR 37-61); immunosuppression 244 (50.5\%)]. BAL was begun in nonintubated patients in 105 (21.7\%) cases. Sixty-seven (13.9\%) patients reached the grade 3 of adverse event or higher. Logistic regression showed that a BAL performed by a non-experienced physician (non-pulmonologist, or intensivist with less than 10 years in the specialty or less than 50 BAL performed) was the main predictor of poor BAL tolerance in non-intubated patients [OR: 3.57 (95\% confidence interval 1.04-12.35); $P=0.04$ ]. A satisfactory BAL input for decision making was observed in 227 (47.0\%) cases and was not predictable using logistic regression.

Conclusions: Adverse events related to BAL in ICU patients are not infrequent nor necessarily benign. Our findings call for an extreme caution, when envisaging a BAL in ICU patients and for a mandatory accompaniment of the less experienced physicians.
\end{abstract}

Keywords: Fiberoptic bronchoscopy, Bronchoalveolar lavage, Multicenter study, Intensive care

\footnotetext{
*Correspondence: thierry.boulain@chr-orleans.fr

1 Service de Médecine Intensive Réanimation, Centre Hospitalier Régional

d'Orléans, 14 Avenue de l'Hôpital CS 86709, 45067 Orléans Cedex 2,

France

Full author information is available at the end of the article
}

The members of the institutional author "Clinical Research in Intensive Care Sepsis Group (CRICS-TRIGGERSEP)" was listed in Acknowledgements section.

\section{Springer}




\section{Introduction}

Bronchoalveolar lavage (BAL) performed during fiberoptic bronchoscopy can help in diagnosing a vast array of lung diseases $[1,2]$. In the intensive care unit (ICU), it is often performed in patients with acute respiratory failure. The main risk brought by fiberoptic bronchoscopy in the critically ill is the worsening of hypoxemia [2-4], but in the few studies focused on fiberoptic bronchoscopy tolerance and comprising a significant number of BAL performed in ICU patients, BAL has been considered well tolerated in most of the cases [5-11]. Meanwhile, as less invasive diagnostic methods exist or are emerging (high-resolution CT scan imaging, molecular microbiological diagnosis on nasopharyngeal swab, or on tracheal aspirates, etc.), the real utility of BAL for the diagnosis of pulmonary diseases encountered in the ICU may be questioned. In immunocompromised patients who represent a large proportion of patients undergoing BAL in the ICU, the diagnostic yield of BAL was reported to be rather low compared to a less invasive approach [12]. Therefore, estimating the benefit-to-risk balance of BAL in the critically ill would be an appreciable adjunct for decision making, when BAL is envisaged.

The objectives of this prospective, non-interventional, multicentre cohort study were to count and describe the adverse events observed during and after BAL in the critically ill to estimate the proportion of patients for whom the BAL fluid analysis allowed therapeutic decision(s) and to search for predisposing factors for either harm or benefit.

\section{Methods}

The study took place in 16 French medical-surgical ICUs (from public, university-affiliated $[n=10]$ or non-university hospitals $[n=6])$ from April 4, 2017 to October 2, 2018, complied with French law for observational studies, was approved by the Comité de Protection des Personnes (Approval number: 17.02.08) and was registered with clinicaltrials.gov (NCT03098888). Patients or next-of-kin and physicians who performed the BAL gave informed consent.

Patients were included if (1) they had an indication to undergo a BAL as decided by their attending intensivist, (2) cellular analysis of BAL fluid by a pathologist was planned, and (3) consent had been obtained. Pregnant women and patients under 18 years of age were excluded. Mini-BALs, BALs performed without bronchoscopy and BAL without cellular analysis by a pathologist were not allowed. Patients were included at time of their first BAL during the ICU stay.

Each center was asked to include at least 15 patients and a maximum of 60 patients. We planned to include

\section{Take-home message}

In the critically ill, bronchoalveolar lavage (BAL) is an aid for decision making in less than $50 \%$ of the cases and is associated with frequent, sometimes serious adverse events. Adverse events and bronchoalveolar fluid of poor quality are observed more frequently, when BAL is performed by the less experienced physicians.

500 patients and BALs (see Online Resource 1 for sample size considerations).

\section{Measurements and data collection}

Data were recorded using paper case report forms filled in by local investigators and/or study nurses and then digitalized in the coordinating center (Orléans). There was no on-site monitoring, but centers could be queried for clarification after centralized checking of data for completeness and consistency. The study was strictly non-interventional and physicians were asked not to modify their usual practice.

We recorded the specialty (pulmonologist or intensivist) of the physician performing the BAL. The physician's experience in terms of years in the specialty $(<5$; $5-10$; $>10$ years) and of number of BAL performed $(<30 ; 30-50 ;>50)$ was recorded. We defined the physician performing the BAL as an "experienced physician" when he/she was a pulmonologist or when he/ she was an intensivist with the greatest experience (i.e., $>10$ years in the specialty or $>50$ BAL performed), considering that pulmonologists, by virtue of their specialty, are sufficiently trained in the practice of BAL. We collected patients' characteristics at inclusion, including demographics, time spent in ICU before BAL, existence of acute respiratory failure before BAL or not, according to the attending intensivist's judgment, Simplified Acute Physiology Score (SAPSII) [13], tobacco use, underlying respiratory diseases, immunosuppression, and use of anticoagulant or antiplatelet therapy. We recorded the indication(s) of BAL, vital signs before BAL (respiratory rate [RR], heart rate [HR], blood pressure $[\mathrm{BP}])$, and arterial blood gases, blood lactate, and pulse oximetry $\left(\mathrm{SpO}_{2}\right)$ within the past $6 \mathrm{~h}$. Type of respiratory support used, body temperature, BP, HR, RR, and $\mathrm{SpO}_{2}$ were collected at the beginning of bronchoscopy and at $1,6,12$, and $24 \mathrm{~h}$, thereafter. The amounts of fluid instilled for BAL and recovered were recorded. If sampled, arterial blood gases corresponding to the lowest $\mathrm{PaO}_{2}$ /inspired fraction of oxygen $\left(\mathrm{FiO}_{2}\right)$ ratio within $24 \mathrm{~h}$ after BAL were also recorded. For patients under oxygen therapy other than high-flow nasal cannula oxygen therapy (HFNC), the $\mathrm{FiO}_{2}$ value was derived from oxygen flow rate [14]. 


\section{Adverse events collection}

BAL respiratory tolerance was first assessed by recording the need for modification(s) in respiratory support as previously described [8] from the beginning of bronchoscopy to $24 \mathrm{~h}$ after, including need of tracheal intubation, increase by more than $50 \%$ in oxygen flow rate, or use of HFNC in patients under standard oxygen therapy, increase by more than $20 \%$ in gas flow rate or $\mathrm{FiO}_{2}$ in patients initially under HFNC, need of non-invasive ventilation (NIV) in patients who initially had no mechanical respiratory support and increase by more than $20 \%$ in inspiratory pressure support or in positive end-expiratory pressure or in $\mathrm{FiO}_{2}$, in patients initially treated by NIV. We added to this list the following events: increase by more than $20 \%$ in inspiratory pressure support or in positive end-expiratory pressure or in $\mathrm{FiO}_{2}$, or need of extracorporeal membrane oxygenation therapy in patients initially treated by invasive mechanical ventilation, and need for switching from pressure support mode to volume-controlled mode in patients with mechanical respiratory support.

In addition, the investigators were asked to declare all clinically significant drops in $\mathrm{SpO}_{2}$ and all other clinically significant events occurring during the $24 \mathrm{~h}$ following the beginning of the bronchoscopy/BAL procedure.

All events were categorized in five grades of increasing severity (see Table 1).

\section{BAL fluid quality}

Pathologists assessed the quality of the BAL fluid. A BAL fluid containing more than $5 \%$ of bronchial (squamous or ciliated epithelial) cells or less than 50,000 cells $/ \mathrm{ml}$ or that was judged non interpretable for other reasons was said of "poor quality". Otherwise, the BAL fluid was considered of "good quality".

\section{BAL input for therapeutic decisions}

The attending intensivists were asked, after having collected all analyses made on BAL fluid, to categorize the BAL according to the highest degree of usefulness it had reached: Class 1, of no help; Class 2, in line with (but not definitively confirming) a diagnosis already mentioned; Class 3 , suggesting a diagnosis not previously envisaged; Class 4, allowing to interrupt one or several treatments; or Class 5, bringing definitive diagnosis and/or allowing the initiation a new therapy.

\section{Statistical analysis}

Categorical variables are expressed as counts and percentages. Continuous variables are expressed as median and interquartile range (IQR) or mean and SD. Variables were compared between groups using $X^{2}$ test, Fisher exact test, Kruskal-Wallis rank sum test, Mann-Whitney $U$ test, one-way analysis of variance, or $t$ test when appropriate.

For multivariable analyses, missing values were replaced using multiple imputation by chained equations, and 100 imputed datasets were pooled and analysed.

Multivariable logistic regressions with centers handled as random effect variable were used to identify predictors of "poor tolerance" (defined as the occurrence of at least one adverse event of grade 3 or higher during the $24 \mathrm{~h}$-period of the study), and of "good usefulness" (degree of usefulness of Class 4 or 5) (See Online Resource 1 for detailed methods of variables/models selection).

Regarding BAL tolerance, predictors were also searched in the framework of an ordinal regression model (proportional odds model) [15] with mixed effects, using the highest grade of adverse event reached by each patient (as defined in Table 1) as an ordered categorical outcome. Odds ratios (OR) are given with their 95\%

Table 1 Classification of adverse event severity

\begin{tabular}{|c|c|}
\hline $\begin{array}{l}\text { Grade } \\
\text { of adverse } \\
\text { event }\end{array}$ & Definitions \\
\hline Grade 0 & No adverse event (for coding and analysis purpose, grade allocated to patients with no adverse event) \\
\hline Grade 1 & $\begin{array}{l}\text { Isolated drop in } \mathrm{SpO}_{2} \text { during } \mathrm{BAL} \text { with no need of change in respiratory support (no change in oxygen flow rate or in } \mathrm{FiO}_{2} \text { or in ventilator } \\
\text { settings) }\end{array}$ \\
\hline Grade 2 & $\begin{array}{l}\text { Need of change in respiratory support (excluding intubation) but no clinically significant respiratory event declared, or clinical adverse } \\
\text { events that did not lead to changes in therapy, regardless they were judged related or not to the BAL procedure }\end{array}$ \\
\hline Grade 3 & $\begin{array}{l}\text { Clinical adverse events that led to change(s) in therapy, including clinically significant respiratory events that need modification(s) in } \\
\text { respiratory support, regardless they were judged related or not to the BAL procedure }\end{array}$ \\
\hline Grade 4 & $\begin{array}{l}\text { Life-threatening conditions (e.g., need of emergent tracheal intubation; shock with need of vasopressor therapy, bradycardia, ventricular } \\
\text { arrhythmia, resuscitated cardiac arrest, etc.) }\end{array}$ \\
\hline Grade 5 & Death within $24 \mathrm{~h}$ \\
\hline
\end{tabular}

$\mathrm{BAL}$ bronchoalveolar lavage, $\mathrm{FiO}_{2}$ inspired fraction of oxygen, $\mathrm{SpO}_{2}$ blood oxygen saturation measured by pulse oximetry 
confidence intervals (95\% CI). Logistic regressions were re-run in pre-specified subgroups: patients under invasive mechanical ventilation or not; BAL performed only for suspicion of hospital-acquired lung infection, or not.

The time courses of RR, HR, BP, and $\mathrm{SpO}_{2}$, from BAL time $(\mathrm{H} 0)$ to $24 \mathrm{~h}$ after $\mathrm{BAL}$, were compared between types of respiratory support used at time of BAL in the framework of distinct linear mixed models, adjusting for initial $\mathrm{PaO}_{2} / \mathrm{FiO}_{2}$ ratio and SAPSII, and patients handled as random effect. In these analyses, $p$ values were adjusted for multiple comparisons using the Tukey's test.

All analyses were conducted using $\mathrm{R}$ software 3.6.0 (http://www.R-project.org). A two-side $p$ value $<0.05$ indicated statistical significance.

\section{Results}

Among the 1234 BAL performed during the study period, $483 \mathrm{BAL}$ in 483 patients were included (Fig. 1). One-third (163/483 [33.7\%]) were performed in patients with chronic pulmonary disease(s) and one half (244/483 [50.5\%]) in patients with immunosuppression. Fifty six (11.6\%) were begun under standard oxygen therapy (with either standard nasal cannula, non-rebreathing, or rebreathing mask), 45 (9.3\%) under HFNC, 4 (0.8\%) under NIV, and 378 (78.3\%) under invasive mechanical ventilation. BAL was predominantly performed by intensivists $(252 / 378$ [66.7\%]) when patients were intubated, and by pulmonologists (74/105 [70.5\%]) otherwise. For one-third of BAL performed under invasive mechanical ventilation, the only indication was the suspicion of ventilator-associated pneumonia (125/378 [33.1\%]). Other characteristics of patients and BAL are exposed in Table 2.

\section{Adverse events}

A total of 224 (46.4\%) patients needed modification of the respiratory support within the $24 \mathrm{~h}$ after the beginning of BAL, including eight (16.3\%) intubations in the HFNC/NIV group and one (1.7\%) in the standard oxygen therapy group. Percentages of patients needing change in the type of respiratory support are shown in Table S2 Online Resource 1. A total of 710 adverse events of any grade were observed (Table 3).

Sixty-seven (13.9\%) patients reached the grade 3 of adverse event or higher in the whole population. More patients in the HFNC/NIV group (17/49 [34.7\%]) and in the standard oxygen therapy group (16/56 [28.6\%]) did so compared to the invasive mechanical ventilation group $(34 / 378$ [9.0\%]) $(p<0.001)$.

Grade 3 adverse events occurred more frequently in non-intubated than in intubated patients (33/105 [31.4\%] vs $34 / 378$ [9.0\%]; $p<0.0001$ ) (Fig. 2). In non-intubated patients, the percentage of Grade 3 adverse events was

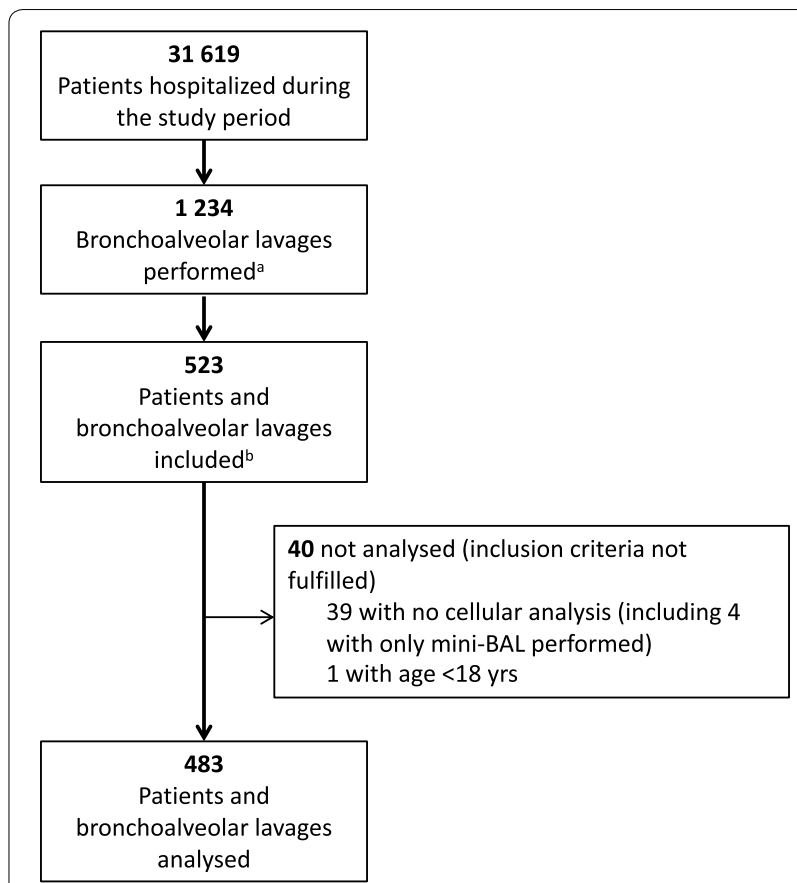

Fig. 1 Study flow chart. a Among the 1234 bronchoalveolar lavages (BAL) performed during the study period, we did not record whether they comprised cellular analysis by a pathologist or if they were mini-BAL or BAL performed with or without bronchoscopy. b Patient recruitment exceeded the 500 expected, because we anticipated a number of non-workable case report forms

$47.1 \%(8 / 17)$ when BAL was performed by a non-experienced physician versus $28.4 \%(25 / 88)$ otherwise, but the difference did not reach statistical significance due to small subsets sizes. Logistic regression showed a strong interaction between the variables "invasive mechanical ventilation" and "experienced physician" $(p<0.0001)$ (Table S3). In the subset of non-intubated patients, a BAL performed by a "non-experienced physician" was significantly associated with an increased risk of grade 3 adverse events occurrence (OR: 3.57 [1.04-12.35]; $p=0.04$ ) (Table S4). Logistic regression disclosed no significant predictor of grade 3 adverse events in the invasive mechanical ventilation group (data not shown).

Proportional odds model analysis performed on the whole population also showed a strong interaction between the variables "invasive mechanical ventilation" and "experienced physician" $(p<0.0001)$ (Table S5). In the subset of non-intubated patients, a BAL performed by a non-experienced physician was significantly associated with an increased risk of adverse events (OR: $1.53[1.01-2.34] ; p=0.04$ ) and $\mathrm{SpO}_{2}$ below $94 \%$ within $6 \mathrm{~h}$ before BAL, when entered as restricted cubic splines, placed the patients at risk of adverse events of grade 3 or higher (Figure S1). No 
Table 2 Patients characteristics stratified by type of respiratory support at the beginning of bronchoscopy for BAL

\begin{tabular}{|c|c|c|c|c|}
\hline & $\begin{array}{l}\text { Standard oxygen therapy } \\
N=56^{\mathrm{a}}\end{array}$ & $\begin{array}{l}\text { Nasal high-flow oxygen } \\
\text { therapy or non-invasive } \\
\text { ventilation } \\
N=49^{\text {b }}\end{array}$ & $\begin{array}{l}\text { Invasive mechani- } \\
\text { cal ventilation } \\
N=378\end{array}$ & $p$ value $^{c}$ \\
\hline Male sex ${ }^{d}$ & $31(55.4)$ & $32(65.3)$ & $258(68.3)$ & 0.16 \\
\hline Age $\left(\right.$ years) ${ }^{e}$ & $64(53-69)$ & $68(56-73)$ & $63(53-72)$ & 0.47 \\
\hline SAPSII & $34(28-45)$ & $40(32-45)$ & $51(40-63)$ & $<0.01$ \\
\hline Acute respiratory failure & $45(80.4)$ & $49(100)$ & $359(95)$ & $<0.01$ \\
\hline Acute respiratory failure for less than 5 days & $30(53.6)$ & $29(59.2)$ & $\begin{array}{l}198 \text { (52.4) } \\
\text { Missing values: } n=1\end{array}$ & 0.90 \\
\hline ICU length of stay before $B A L<5$ days & $46(82.1)$ & $42(85.7)$ & $\begin{array}{l}221(58.5) \\
\text { Missing values: } n=1\end{array}$ & $<0.01$ \\
\hline \multicolumn{5}{|l|}{ Underlying respiratory diseases } \\
\hline Cigarette smoking & $11(19.6)$ & $8(16.3)$ & $112(29.6)$ & 0.06 \\
\hline Chronic restrictive pulmonary disease & $4(7.1)$ & $4(8.2)$ & $41(10.8)$ & 0.62 \\
\hline Chronic obstructive pulmonary disease & $8(14.3)$ & $13(26.5)$ & $77(20.4)$ & 0.30 \\
\hline Asthma & $6(10.7)$ & $2(4.1)$ & $11(2.9)$ & 0.02 \\
\hline Home oxygen therapy & 0 & $1(2)$ & $14(3.7)$ & 0.30 \\
\hline Sleep apnea syndrome & $6(10.7)$ & $3(6.1)$ & $31(8.2)$ & 0.69 \\
\hline Home positive pressure ventilation & $2(3.6)$ & $2(4.1)$ & $24(6.3)$ & 0.61 \\
\hline \multicolumn{5}{|l|}{ Immunosuppression } \\
\hline All causes & $34(60.7)$ & $36(73.5)$ & $174(46)$ & $<0.01$ \\
\hline Active solid organ cancer & $6(10.7)$ & $10(20.4)$ & $48(12.7)$ & 0.27 \\
\hline Hematological malignancy & $19(33.9)$ & $14(28.6)$ & $63(16.7)$ & $<0.01$ \\
\hline $\begin{array}{l}\text { Radiotherapy or chemotherapy within the past } \\
6 \text { months }\end{array}$ & $22(39.3)$ & $15(30.6)$ & $77(20.4)$ & $<0.01$ \\
\hline Neutropenia $^{f}$ & $6(10.7)$ & $6(12.2)$ & $23(6.1)$ & 0.17 \\
\hline HIV-positive & $3(5.4)$ & $1(2)$ & $11(2.9)$ & 0.56 \\
\hline Solid organ transplantation & $10(17.9)$ & $9(18.4)$ & $42(11.1)$ & 0.16 \\
\hline Corticosteroid therapy & $13(23.2)$ & $14(28.6)$ & $71(18.8)$ & 0.23 \\
\hline Others immunosuppressive drugs & $15(26.3)$ & $24(49)$ & $88(23.3)$ & $<0.01$ \\
\hline \multicolumn{5}{|l|}{ Anticoagulant therapy } \\
\hline Curative anticoagulant therapy ${ }^{9}$ & $9(15.8)$ & $12(24.5)$ & $68(18)$ & 0.47 \\
\hline $\begin{array}{l}\text { Anticoagulant therapy for venous thromboembo- } \\
\text { lism prevention }\end{array}$ & $17(30.4)$ & $17(34.7)$ & $154(40.7)$ & 0.27 \\
\hline Antiplatelet therapy (including aspirin) & $7(12.3)$ & $4(8.2)$ & 75 (19.9) & 0.07 \\
\hline \multicolumn{5}{|l|}{ Indications for $\mathrm{BAL}^{\mathrm{h}}$} \\
\hline Community-acquired pneumonia & $25(44.6)$ & $27(55.1)$ & $141(37.3)$ & 0.04 \\
\hline Suspicion of hospital-acquired lung infection & $11(19.6)$ & $8(16.3)$ & $202(53.4)$ & $<0.01$ \\
\hline $\begin{array}{l}\text { Including hospital- or ventilator-associated pneu- } \\
\text { monia as the sole indication }\end{array}$ & $6(10.7)$ & $2(4.1)$ & $125(33.1)$ & $<0.01$ \\
\hline Suspicion of diffuse parenchymal lung disease & $20(35.7)$ & $29(59.2)$ & $104(27.5)$ & $<0.01$ \\
\hline Lung infiltrate of possible non-infectious origin & $17(30.4)$ & $11(22.4)$ & $72(19)$ & 0.14 \\
\hline Other indication & $7(12.5)$ & $4(8.2)$ & $42(11.1)$ & 0.77 \\
\hline Arterial blood gas analysis within $6 \mathrm{~h}$ before BAL & Missing values: $n=11$ & Missing values: $n=1$ & Missing values: $n=13$ & \\
\hline $\mathrm{pH}$ & $7.45(7.42-7.47)$ & $7.46(7.43-7.48)$ & $7.38(7.31-7.45)$ & $<0.01$ \\
\hline $\mathrm{PaCO}_{2}(\mathrm{mmHg})$ & $35.0(31.6-40)$ & $36.6(32.5-41)$ & $42(37.0-50.9)$ & $<0.01$ \\
\hline $\mathrm{PaO}_{2}(\mathrm{mmHg})$ & $73.0(64.8-89)$ & $75.00(59.8-97.4)$ & $80.6(67-98)$ & 0.07 \\
\hline $\mathrm{PaO}_{2} / \mathrm{FiO}_{2}$ ratio & $203(147-326)^{i}$ & $135(102-183)$ & $150(103-228)$ & $<0.01$ \\
\hline \multicolumn{5}{|l|}{ Initial clinical characteristics } \\
\hline Lowest $\mathrm{SpO}_{2}(\%)$ within $6 \mathrm{~h}$ before $\mathrm{BAL}$ & $95(91-97)$ & $93(90-96)$ & $95(91-98)$ & 0.11 \\
\hline Highest respiratory rate within $6 \mathrm{~h}$ before BAL & $27(23-30)$ & $\begin{array}{l}25(23-31) \\
\text { Missing values: } n=2\end{array}$ & $\begin{array}{l}25(22-32) \\
\text { Missing values: } n=3\end{array}$ & 0.95 \\
\hline
\end{tabular}


Table 2 (continued)

\begin{tabular}{|c|c|c|c|c|}
\hline & $\begin{array}{l}\text { Standard oxygen therapy } \\
N=56^{\mathrm{a}}\end{array}$ & $\begin{array}{l}\text { Nasal high-flow oxygen } \\
\text { therapy or non-invasive } \\
\text { ventilation } \\
N=49^{b}\end{array}$ & $\begin{array}{l}\text { Invasive mechani- } \\
\text { cal ventilation } \\
N=378\end{array}$ & $p$ value $^{c}$ \\
\hline Blood lactate $(\mathrm{mmol} / \mathrm{l})$ within $6 \mathrm{~h}$ before BAL & $\begin{array}{l}1.3(0.8-1.8) \\
\text { Missing values: } n=17\end{array}$ & $\begin{array}{l}1.3(0.9-1.8) \\
\text { Missing values: } n=6\end{array}$ & $\begin{array}{l}1.5(1.1-2.2) \\
\text { Missing values: } n=37\end{array}$ & 0.02 \\
\hline \multicolumn{5}{|l|}{ Vital signs at $\mathrm{HO}^{\mathrm{j}}$} \\
\hline Body temperature $\left({ }^{\circ} \mathrm{C}\right)$ & $\begin{array}{l}37.4 \text { (1) } \\
\text { Missing values: } n=3\end{array}$ & $\begin{array}{l}37.4(0.8) \\
\text { Missing values: } n=2\end{array}$ & $\begin{array}{l}37.3(1.1) \\
\text { Missing values: } n=12\end{array}$ & 0.85 \\
\hline Respiratory rate (cycles/min) & $\begin{array}{l}24(6) \\
\text { Missing values: } n=1\end{array}$ & $25(6)$ & $\begin{array}{l}24 \text { (8) } \\
\text { Missing values: } n=5\end{array}$ & 0.74 \\
\hline Heart rate (b./min) & $100(22)$ & $98(22)$ & $99(23)$ & 0.91 \\
\hline $\mathrm{SpO}_{2}(\%)$ & $96(4)$ & $\begin{array}{l}97(3) \\
\text { Missing values: } n=1\end{array}$ & $\begin{array}{l}97 \text { (7) } \\
\text { Missing values: } n=4\end{array}$ & 0.47 \\
\hline Mean arterial blood pressure $(\mathrm{mmHg})$ & $91(19)$ & $86(18)$ & $\begin{array}{l}78(16) \\
\text { Missing values: } n=2\end{array}$ & $<0.01$ \\
\hline \multicolumn{5}{|l|}{ BAL procedure } \\
\hline Amount of fluid instilled (ml) & $150(100-150)$ & $150(120-150)$ & $\begin{array}{l}150(100-150) \\
\text { Missing values: } n=11\end{array}$ & 0.15 \\
\hline Amount of fluid recovered (ml) & $48(30-69)$ & $40(30-70)$ & $\begin{array}{l}45(30-60) \\
\text { Missing values: } n=11\end{array}$ & 0.92 \\
\hline Duration of the BAL procedure (min) & $\begin{array}{l}12(9-15) \\
\text { Missing values: } n=2\end{array}$ & $\begin{array}{l}10(8-15) \\
\text { Missing values: } n=1\end{array}$ & $\begin{array}{l}15(10-20) \\
\text { Missing values: } n=19\end{array}$ & $<0.01$ \\
\hline Time taken for BAL fluid to reach the laboratory & Missing values: $n=1$ & & Missing values: $n=7$ & \\
\hline Less than $2 \mathrm{~h}$ & $46(82.1)$ & $45(91.8)$ & $290(76.7)$ & 0.58 \\
\hline Between 2 and $4 \mathrm{~h}$ & $3(5.4)$ & $1(2)$ & $37(9.8)$ & 0.14 \\
\hline More than $4 \mathrm{~h}$ & $6(10.7)$ & $3(6.1)$ & $44(11.6)$ & 0.51 \\
\hline \multicolumn{5}{|c|}{ Specialty and experience ${ }^{k}$ of the physician performing the bronchoscopy and BAL } \\
\hline Pulmonologist & $37(66.1)$ & $37(75.5)$ & $126(33.3)$ & $<0.01$ \\
\hline Intensivist & $19(33.9)$ & $12(24.5)$ & $252(66.7)$ & $<0.01$ \\
\hline Experienced physician & $45(80.4)$ & $43(87.8)$ & $205(54.2)$ & 0.01 \\
\hline
\end{tabular}

SAPSII Simplified Acute Physiology Score, ICU intensive care unit, BAL bronchoalveolar lavage

a Including 45 (80.4\%) patients under oxygen therapy via standard nasal cannula or non-rebreathing mask, and 11 patients (19.6\%) under oxygen therapy via rebreathing mask

b Including only four patients (8.2\%) under non-invasive ventilation

c Groups were compared using $x^{2}$ test for proportions, Kruskal-Wallis rank sum test or one-way analysis of variance for continuous variables. $p$ values were non adjusted for multiple testing and should be considered exploratory

d Categorical variables are expressed as count and (\%)

e Continuous variables are expressed as median (interquartile range) or mean (SD)

f Absolute neutrophil count $<1000 / \mu \mathrm{L}$

g Anticoagulant therapy for either recent thromboembolic event or for prevention of arterial thromboembolism (e.g., atrial fibrillation, mechanical heart valve, etc.)

h More than one indication could be present for each BAL

i Significantly higher than in the nasal high-flow oxygen therapy or non-invasive ventilation group $(p<0.001)$, and then in the invasive mechanical ventilation group $(p=0.001)$

j $\mathrm{HO}$ indicates the time at which BAL has began

${ }^{k}$ Experience in years in the specialty and in terms of number of BAL performed are detailed in Table S1 of the Online resource 1

' We defined the physician performing the BAL as an "experienced physician" when he/she was a pulmonologist or when he/she was an intensivist with the greatest experience (i.e., $>10$ years in the specialty or $>50$ BAL performed)

statistically significant predictor of adverse events could be identified in the invasive mechanical ventilation group (data not shown).

\section{Quality of BAL fluid collected}

The median amount of fluid instilled during BAL did not differ between BAL performed only for suspicion of hospital-acquired infection (140 ml [100-150]) or not 


\section{Table 3 Counts and percentages of adverse events}

\begin{tabular}{|c|c|c|c|c|}
\hline & $\begin{array}{l}\text { Standard oxygen } \\
\text { therapy } \\
N=56^{\mathrm{a}}\end{array}$ & $\begin{array}{l}\text { High-flow nasal cannula oxygen } \\
\text { therapy or non-invasive ventilation } \\
N=49^{b}\end{array}$ & $\begin{array}{l}\text { Invasive mechanical } \\
\text { ventilation } \\
N=378\end{array}$ & $p$ value $^{c}$ \\
\hline \multicolumn{5}{|l|}{ Highest grade of adverse event reached ${ }^{d}$} \\
\hline Grade 0 (no adverse event) & $4(7.1)$ & $8(16.3)$ & $56(14.8)$ & 0.27 \\
\hline Grade 1 & $6(10.7)$ & $1(2)$ & $44(11.6)$ & 0.12 \\
\hline Grade 2 & $30(53.6)$ & $23(46.9)$ & $244(64.6)$ & 0.025 \\
\hline Grade 3 & $15(26.8)$ & $9(18.4)$ & $19(5)$ & $<0.001$ \\
\hline Grade 4 & $1(1.8)$ & $7(14.3)$ & $3(0.8)$ & $<0.001$ \\
\hline Grade 5 (death within 24 h) & 0 & $1(2)$ & $12(3.2)$ & 0.37 \\
\hline Grade reached $=3$ or higher & $16(28.6)$ & $17(34.7)$ & $34(9)$ & $<0.001$ \\
\hline \multicolumn{5}{|l|}{ Details of adverse events } \\
\hline Modification in respiratory support ${ }^{\mathrm{e}}$ & $17(30.4)$ & $29(59.2)$ & $178(47.1)$ & 0.01 \\
\hline Including tracheal intubation & $1(1.7)$ & $8(16.3)^{f}$ & - & 0.01 \\
\hline \multicolumn{5}{|l|}{ Events during BAL procedure } \\
\hline Agitation & $4(7.1)$ & 0 & $6(1.6)$ & 0.01 \\
\hline Respiratory distress ${ }^{9}$ & $8(14.3)$ & $4(8.2)$ & $13(3.4)$ & $<0.01$ \\
\hline Bronchospasm & $2(3.6)$ & 0 & $4(1.1)$ & 0.20 \\
\hline Cough & $12(21.4)$ & $4(8.2)$ & $10(2.6)$ & $<0.01$ \\
\hline Laryngospasm & 0 & $1(2)$ & - & 0.47 \\
\hline Significant drop in $\mathrm{SpO}_{2}^{\mathrm{h}}$ & $14(25)$ & $2(4.1)$ & $48(12.7)$ & $<0.01$ \\
\hline Arrhythmia or tachycardia $\geq 150 \mathrm{~b} . / \mathrm{min}$ & 0 & 0 & $2(0.5)$ & 0.76 \\
\hline Hypotension (systolic BP < 90 mmHg) & 0 & 0 & $16(4.2)$ & 0.10 \\
\hline Hypertension (systolic BP > 180 mmHg) & $2(3.6)$ & $2(4.1)$ & $10(2.6)$ & 0.81 \\
\hline Epistaxis & $1(1.8)$ & 0 & 0 & 0.02 \\
\hline Vomiting & $2(3.6)$ & 0 & 0 & $<0.01$ \\
\hline Mild bronchial hemorrhage & $1(1.8)$ & $2(4.1)$ & $6(1.6)$ & 0.48 \\
\hline Severe bradycardia & 0 & 0 & $1(0.3)$ & 0.87 \\
\hline Cardiac arrest & 0 & 0 & $1(0.3)$ & 0.87 \\
\hline \multicolumn{5}{|l|}{ Events within $24 \mathrm{~h}$ after BAL } \\
\hline $1{ }^{\circ} \mathrm{C}$ rise in body temperature & $10(17.9)$ & $11(22.4)$ & $82(21.7)$ & 0.79 \\
\hline Body temperature increase above $38.5^{\circ} \mathrm{C}$ & $9(16.1)$ & $12(24.5)$ & $52(13.8)$ & 0.14 \\
\hline Agitation & $1(1.8)$ & 0 & $7(1.9)$ & 0.63 \\
\hline Significant drop in $\mathrm{SpO}_{2}^{\mathrm{h}}$ & $9(16.1)$ & $5(10.2)$ & $46(12.2)$ & 0.63 \\
\hline Tachycardia $\geq 150 \mathrm{~b} . / \mathrm{min}$ & $1(1.8)$ & $1(2)$ & $11(2.9)$ & 0.85 \\
\hline Hypotension (systolic BP < 90 mmHg) & $12(21.4)$ & 14 (28.6) & $132(34.9)$ & 0.11 \\
\hline Hypertension (systolic BP > 180 mmHg) & $5(8.9)$ & $3(6.1)$ & $13(3.4)$ & 0.14 \\
\hline Need of ECMO therapy & 0 & 0 & $13(3.4)$ & 0.20 \\
\hline Death & 0 & $1(2)$ & $12(3.2)$ & 0.37 \\
\hline
\end{tabular}

$B A L$ bronchoalveolar lavage, $B P$ blood pressure, $E C M O$ extracorporeal membrane oxygenation

${ }^{a}$ Including 45 (80.4\%) patients under oxygen therapy via standard nasal cannula or non-rebreathing mask, and 11 patients (19.6\%) under oxygen therapy via rebreathing mask

${ }^{\mathrm{b}}$ Including only four patients (8.2\%) under non-invasive ventilation

c Groups were compared using $x^{2}$ test or Fisher exact test. $p$ values were not adjusted for multiple testing and should be considered exploratory

d See Table 1 for definitions of grades of adverse events

e See text for definitions

${ }^{f}$ Including seven intubations in patients under nasal high-flow oxygen therapy and one in the four patients under non-invasive ventilation

9 "Respiratory distress" as declared by the investigators. In all cases, "respiratory distress" needed modification of the respiratory support (see "Methods" section for definition)

h Drop in $\mathrm{SpO}_{2}$ as declared by the investigators. In all cases, drop in $\mathrm{SpO}_{2}$ needed modification of the respiratory support (see "Methods" section for definition) 


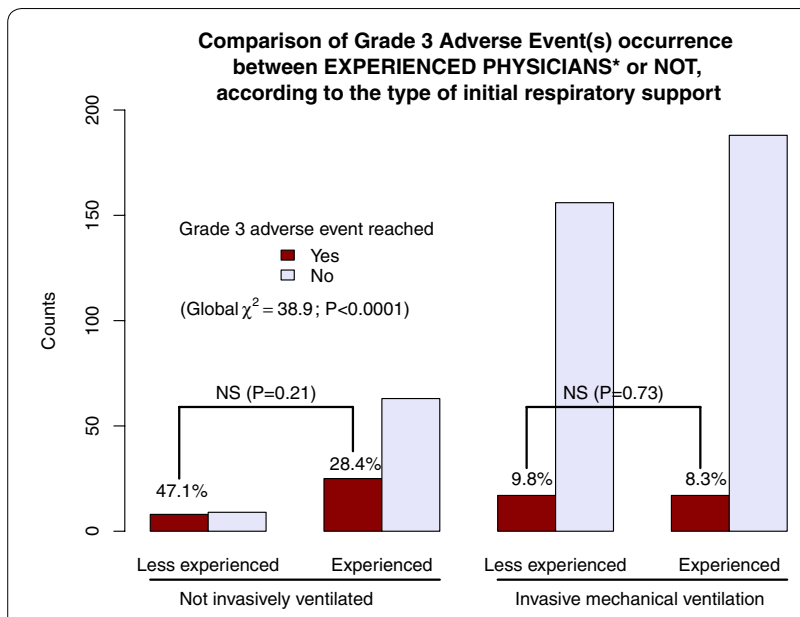

Fig. 2 Counts and percentages of grade 3 adverse event(s) during or after BAL according to physician's experience and type of initial respiratory support. NS not significant. We defined the physician performing the BAL as an "experienced physician" when he/she was a pulmonologist or when he/she was an intensivist with the greatest experience (i.e., > 10 years in the specialty or $>50 \mathrm{BAL}$ performed)

(150 ml [100-150]) $(p=0.60)$, and did not differ across the different types of respiratory support used (Table 2). The median amount of BAL fluid recovered was $45 \mathrm{ml}$ (IQR 30-62) (range 5-200) and did not differ across the different types of respiratory support used (Table 2).

The pathologists declared the BAL fluid as of good quality in $327 / 483(67.7 \%)$ cases (Table 4$)$. This percentage was significantly higher when the physician was a pulmonologist $(156 / 200$ [78\%]) than when he/she was an intensivist $(171 / 283[60.4 \%]) \quad(p<0.001)$. Logistic regression showed that the variable "experienced physician" (OR 2.17 [1.35-3.50]; $p=0.002$ ) and the amount of BAL fluid (in $\mathrm{ml}$ ) recovered handled as a linear predictor (OR 1.02 [1.01-1.03] per $1 \mathrm{ml}$ increase; $p<0.01$ ), were statistically significant predictors of a BAL fluid of good quality (Table S6). Transforming the amount of BAL fluid in restricted cubic splines to take into account potential non-linearity gave a slightly better model fit and showed a biphasic relationship between the amount of BAL fluid recovered and the probability of obtaining a BAL of good quality (Fig. 3). The same biphasic relationship was also founded in intubated patients (Figure S2), in non-intubated patients (Figure S3), and in patients for whom the BAL was not performed only for suspicion of hospital-acquired lung infection (Figure S4). No statistically significant predictor of a BAL of good quality could be identified in patients for whom a suspicion of hospitalacquired lung infection was the sole indication of BAL (data not shown).

\section{BAL input for diagnosis and decision making}

Diagnoses retained for explaining the lung disease that justified the performance of BAL are exposed in Tables S7, S8, S9, and S10 in the Online Resource 1. BAL input was classified in Class 1 (not useful) in 185 patients out of 483 (38.3\%) (Table 4) and in more than one-third of patients with BAL performed only for suspicion of hospital-acquired lung infection (45/133 [38.3\%]). In the whole

Table 4 Bronchoalveolar lavage input for diagnosis and decision making

\begin{tabular}{|c|c|c|c|c|}
\hline & $\begin{array}{l}\text { Standard oxy- } \\
\text { gen therapy } \\
N=56^{\mathrm{a}}\end{array}$ & $\begin{array}{l}\text { High-flow nasal cannula oxygen } \\
\text { therapy or non-invasive ventilation } \\
N=49^{b}\end{array}$ & $\begin{array}{l}\text { Invasive mechani- } \\
\text { cal ventilation } \\
N=378\end{array}$ & $p$ value $^{c}$ \\
\hline BAL fluid of good quality ${ }^{d}$ as declared by the pathologist & $42(75)$ & $36(73.5)$ & $249(65.9)$ & 0.26 \\
\hline \multicolumn{5}{|l|}{ Highest class of BAL input reached } \\
\hline Class 1: brings no useful information & $19(33.9)$ & $17(34.7)$ & $149(39.4)$ & 0.63 \\
\hline Class 2: in line with a diagnosis already mentioned & $3(5.4)$ & $6(12.2)$ & $48(12.7)$ & 0.28 \\
\hline Class 3: suggests a diagnosis not previously envisaged & $2(3.6)$ & $1(2)$ & $11(2.9)$ & 0.90 \\
\hline Class 4: allows discontinuing one or several treatments & $11(19.6)$ & $6(12.2)$ & $20(5.3)$ & $<0.01$ \\
\hline $\begin{array}{l}\text { Class 5: brings definitive diagnosis and/or allows new } \\
\text { therapy initiation }\end{array}$ & $21(37.5)$ & $19(38.8)$ & $150(39.7)$ & 0.95 \\
\hline Class 4 or 5 reached ${ }^{e}$ & $32(57.1)$ & $25(51)$ & $170(45)$ & 0.20 \\
\hline \multicolumn{5}{|l|}{ Numbers indicate counts and (\%) } \\
\hline \multicolumn{5}{|l|}{$B A L$ bronchoalveolar lavage } \\
\hline \multicolumn{5}{|c|}{$\begin{array}{l}\text { a Including } 45(80.4 \%) \text { patients under oxygen therapy via standard nasal cannula or non-rebreathing mask, and } 11 \text { patients (19.6\%) under oxygen therapy via } \\
\text { rebreathing mask }\end{array}$} \\
\hline \multicolumn{5}{|c|}{ b Including only four patients (8.2\%) under non-invasive ventilation } \\
\hline \multicolumn{5}{|l|}{${ }^{c}$ Groups were compared using $x^{2}$ test } \\
\hline \multicolumn{5}{|l|}{ d See text for definition of "good quality" for BAL fluid } \\
\hline e Class 4 or 5 BAL contribution to diagnosis and decision ma & & & & \\
\hline
\end{tabular}




\section{Probability of BAL of good quality}

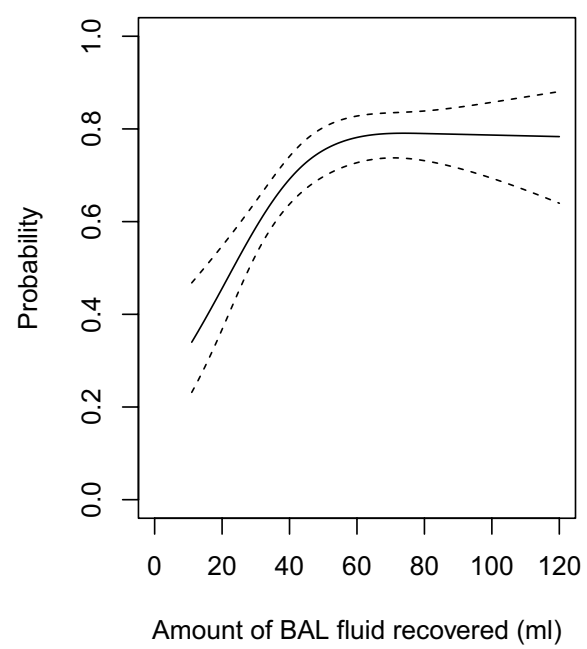

Fig. 3 Predicted probability of obtaining a BAL of good quality according to the amount of BAL fluid recovered in the whole study population. BAL bronchoalveolar lavage. For this estimation of the probability of obtaining a BAL of good quality, logistic regression adjusted for all covariables (see Table 56 in Online Resource 1) was used. The amount of BAL fluid recovered was transformed in cubic splines to account for non-linearity. The biphasic shape of the figure shows that below $60 \mathrm{~mL}$ of BAL fluid recovered, the estimated probability declines in parallel with the amount of fluid recovered

population, BAL classified as Class 1 showed a frequency of adverse events of grade 3 or higher not different from that of BAL not classified Class 1 (21/185 [11.4\%] vs. 46/298 [15.4\%], respectively; $p=0.20)$.

There were 227/483 (47.0\%) BAL classified as of good usefulness (i.e., Class 4 or 5) in the whole population. This frequency was not statistically different between intubated and non-intubated patients at time of BAL or between patients with BAL performed only for suspicion of hospital-acquired lung infection or not (Table S11).

The quality of the BAL fluid collected was not statistically associated with the BAL usefulness: $49.5 \%(162 / 327)$ of BAL judged of good quality were classified in Class 4 or 5 , versus $41.7 \%(65 / 156)$ when BAL was not judged of good quality by the pathologist $(p=0.12)$.

Multivariable logistic regression did not identify statistically significant predictors of a BAL of Class 4 or 5 (data not shown), either in the whole population or in pre-specified subsets.

\section{Course of vital signs and blood gases during the 24-h study period}

Linear mixed model analysis showed that baseline and further $\mathrm{SpO}_{2}$ values were lower in the standard oxygen group than in the two other types of respiratory support. Other details of analyses are reported in Figure S5.

\section{Discussion}

In this multicenter cohort of critically ill patients, numerous adverse events were observed during or after BAL and grade 3 adverse events affected $13.9 \%$ of the study population. The association of the noninvasiveness of respiratory support used with a BAL performed by a nonexperienced physician was a strong predictor of adverse events occurrence. The experience of the physician performing the BAL and the amount of BAL fluid recovered were the main predictors of a BAL fluid judged as of good quality by the pathologist. The BAL input for decision making was satisfactory (i.e., allowed discontinuing a treatment and/or initiating a new one) in less than 50\% of the cases. Even when BAL was indicated only for suspicion of hospital-acquired lung infection, a case where BAL fluid quality might have less importance since most often mainly microbiological information is expected, the BAL input was satisfactory in 53\% (71/133) of the cases.

Interestingly, among the 49 non-intubated patients with the most severe respiratory failure, for whom clinicians had judged standard oxygen therapy was not sufficient, only $4(8.2 \%)$ had BAL performed under NIV, while the remaining patients had BAL performed under HFNC therapy. In high-risk patients, NIV for fiberoptic bronchoscopy with BAL has been shown feasible $[16,17]$ and recently, in one small-size randomized trial, safer than HFNC therapy [18]. In counterpart, HFNC therapy has been shown safer than NIV in patients with severe hypoxemic respiratory failure [19] and has the advantage to be easy to use for care providers. This probably explains the predominant use of HFNC therapy in our study cohort. However, while some recent studies suggested that HFNC is safe for performing fiberoptic bronchoscopy and BAL [20-22], large randomized trials are still needed.

In the present study, adverse events collected were more frequent than in several previous studies $[5-8,10]$. This discrepancy may be due to differences in methods used for collecting and defining adverse events. However, while the non-comparative design of this study does not allow firm conclusions regarding the cause-effect relationship between BAL and the collected adverse events, the high frequency of adverse events should prompt caution when performing BAL in ICU patients, especially in non-intubated patients. The high frequency of adverse events might account for the increased hospital mortality recently observed in non-ventilated immunocompromised patients who underwent a bronchoscopy as compared to those who did not [23]. Given the high frequency of adverse events we observed in non-ventilated 
patients, one may wonder if systematically intubating the sickest patients (e.g., those with profound hypoxemia) could not be a safer option for performing BAL. However, although this is a common concern in ICUs, to our knowledge, no comparative trial has yet been conducted to answer this question. It is worth noting that in the few available prospective studies focused on BAL tolerance that showed rather low adverse event rate [6-8], bronchoscopies and BAL were mostly performed by pulmonologists [6] or by experienced ICU physicians [7, 8]. The present study highlights the importance of the physician's experience and training, which have often been emphasized in recommendations [2, 24, 25] for bronchoscopy but have never been demonstrated for ICU patients undergoing BAL so far.

Although we could not show a direct link between the quality of the BAL fluid recovered and the diagnostic yield of BAL, the fact that the variable "experienced physician" was also a strong predictor of a BAL of good quality suggests that the greater the experience of the physician performing the BAL, the better the chance of performing a safe and useful BAL.

Previous studies have reported that the diagnostic yield of BAL was within the range of $34-59 \%$ in ICU patients $[8,11,12]$. In line with these results, using a pragmatical classification in an unselected population, we found that the BAL showed good usefulness for decision making in one half of the cases. Additionally, we found that the BAL input for decision making was not easily predictable. This uncertainty associated with the BAL input for decision making again justifies the caution with which BAL should be performed to ensure the best possible benefit-to-risk balance. Although the BAL usefulness of $47 \%$ observed in this study may appear rather low compared to the number of adverse events brought about, it should be placed in perspective with other diagnostic, invasive procedures such as open lung biopsy. In a recent meta-analysis in acute respiratory distress syndrome patients [26], open lung biopsy was reported to yield definitive diagnosis in nearly $100 \%$ of the cases, allowing to change therapy in $73 \%$, while causing complications in $22 \%$, resulting in a more favorable benefit-to-harm ratio than the one we observed for BAL. However, great variability of diagnostic yield $(40-100 \%)$, impact on therapy $(40-100 \%)$ and complications $(0-60 \%)$ of lung biopsy existed between the published cohort studies [26], preventing any definitive conclusion. Moreover, as those studies were mostly retrospective, it is highly probable that many adverse events were not collected. Therefore, prospective studies that could help in deciding which procedure is riskier or more beneficial to patients are still lacking. In addition, although open lung biopsy may have proved beneficial to some immunosuppressed patients such as after bone marrow transplantation [27], it cannot reasonably be offered to all patients for whom BAL currently appears to be the most appropriate diagnostic tool, either because it may be disproportionate for patients with low severity of disease or because surgical procedures are a real challenge for cancer patients with pancytopenia. Undoubtedly, if there is one alternative to the BAL that could be less risky for immunosuppressed patients, it is the combination of non-invasive tests on sputum, nasopharyngeal secretions, urine, and blood that may dramatically restrict the number of patients for whom BAL is absolutely needed [12]. This might become increasingly true in view of the current development of molecular diagnostic tools [28-30], the knowledge acquired in chest highresolution computed tomography imaging [31, 32], and perhaps future progress in the human volatilome analysis [33].

This study has several limitations. First, because we did not study any control group in parallel, the adverse events collected cannot be attributed to bronchoscopy or to the BAL with certainty. However, all the events collected are known side effects of bronchoscopy or BAL and the close temporal relationship between BAL and adverse events suggests that a non-negligible part of these events were related to the BAL. Second, we did not record the anesthesia regimen used during bronchoscopy and could not differentiate local from general anesthesia. Some adverse events (e.g., hypotension) probably were side effects of intravenous anesthesia. Anyway, our aim was to record, in real-life conditions, adverse events possibly related to the BAL procedure, of which anesthesia is an integral part [2]. Conversely, the occurrence of adverse events such as hypertension, agitation, cough, or bronchospasm, at least in intubated patients, may reflect suboptimal anesthesia and leaves room for improvement. This suggests that in addition to an experienced physician performing the BAL, the systematic presence of a second physician adjusting anesthesia, adapting ventilatory support and taking care of the hemodynamic status, might improve the patient safety. Third, as there are no published specific classifications of adverse events and of diagnostic yield of BAL, we used our own classifications. Regarding the adverse events (Table 1), it is noteworthy that the main predictor of adverse events identified (non-experienced physician performing a BAL in a non-intubated patient), not only was strongly associated with grade 3 adverse events, but also by proportional odds model analysis was associated with an increased probability of observing any grade of adverse event above a certain value versus observing any grade of adverse event below the same value. In our view, this would tend to validate the adverse events classification we proposed. Fourth, we used a "home-made" classification of the BAL input for 
decision making. This may have introduced bias in the estimation of the diagnostic yield of BAL. In particular for the diagnosis of ventilator-associated pneumonia, it is possible that the culture of the BAL fluid identified a microorganism already identified by other means (e.g., tracheal aspirate with semi-quantitative culture) and did not lead to modification of the antibiotic regimen already in place. Although some may argue that in this case the diagnostic yield of BAL might have been declared as very good, there is an ongoing debate about the bacteriological samples to be used for accurately diagnosing ventilatorassociated pneumonia [34, 35]. Also, in some instances despite no formal respiratory diagnosis was retained, the input of BAL was classified as Class 5 (i.e., the best possible) by the attending intensivists, because BAL not only has allowed ruling out some diagnoses, but also allowed trying another treatment such as diuretics or corticosteroids. This may have slightly distorted the classification of the BAL input. Fifth, in the French ICUs involved in this study, the bronchoscopy and BAL could be performed either by pulmonologists or intensivists. Therefore, our results may not be found in countries, where performing bronchoscopy is a prerogative exclusively reserved for pulmonologists.

\section{Conclusion}

Our findings suggest that in real-life conditions, adverse events during or following BAL in ICU patients are not infrequent nor necessarily benign. The lack of experience of the physician performing the BAL was identified as the main predictor of clinically significant adverse events in non-intubated patients. On the other hand, the diagnostic yield of BAL could be considered satisfactory in less than one half of the cases. Altogether, these findings call for an extreme caution when considering the indication of BAL in ICU patients and for a mandatory accompaniment of the less experienced physicians.

\section{Electronic supplementary material}

The online version of this article (https://doi.org/10.1007/s00134-019-05896-4) contains supplementary material, which is available to authorized users.

\footnotetext{
Author details

${ }^{1}$ Service de Médecine Intensive Réanimation, Centre Hospitalier Régional d'Orléans, 14 Avenue de l'Hôpital CS 86709, 45067 Orléans Cedex 2, France. ${ }^{2} \mathrm{CHU}$ de Strasbourg-Hôpital Civil, Service de Réanimation Médicale 1, Place de l'Hôpital, BP 426, 67091 Strasbourg Cedex, France. ${ }^{3}$ Médecine intensive Réanimation, Hôpital de Haute pierre, Hôpitaux Universitaires de Strasbourg, Avenue Molière, 67098 Strasbourg Cedex, France. ${ }^{4} \mathrm{CHU}$ d'Angers Service de Réanimation Médicale et de Médecine Hyperbare, 4, Rue Larrey, 49933 Angers Cedex 09, France. ${ }^{5}$ CHRU de Tours-Hôpital Bretonneau Service de Réanimation Polyvalente, 2 bis, Boulevard Tonnelle, 37044 Tours Cedex 09, France. ${ }^{6}$ Médecine Intensive Réanimation, Réanimation des Urgences CHU la Timone 2-Pole RUSH, 264 Rue Saint Pierre, 13005 Marseille, France. ${ }^{7} \mathrm{CH}$ d'Argenteuil Service de Réanimation Polyvalente, 69, Rue du Lieutenant-Colonel Prudhon, 95107 Argenteuil Cedex, France. ${ }^{8}$ Assistance Publique-Hôpitaux de Marseille, Hôpital Nord, Médecine Intensive Réanimation, 13015 Marseille,
}

France. ${ }^{9}$ Aix-Marseille Université, Faculté de médecine, Centre d'Etudes et de Recherches sur les Services de Santé et qualité de vie, EA 3279, 13005 Marseille, France. ${ }^{10}$ Médecine intensive et Réanimation, $\mathrm{CHU}$ de Poitiers, 2 rue de la Milétrie, 86021 Poitiers, France. ${ }^{11}$ INSERM U1402, Groupe ALIVE, Université de Poitiers, 2 rue de la Milétrie, 86021 Poitiers, France. ${ }^{12} \mathrm{CH}$ de La RochelleHôpital Saint-Louis Service de Réanimation Polyvalente, Rue du Docteur Schweitzer, 17019 La Rochelle Cedex 01, France. ${ }^{13}$ Service de Médecine Intensive Réanimation, CHU de Nantes-Hôtel Dieu, 30 Bd. Jean Monnet, 44093 Nantes Cedex 1, France. ${ }^{14} \mathrm{CHU}$ de Dijon-Complexe du Bocage, Service de Réanimation Médicale, 2 Boulevard Maréchal de Lattre de Tassigny, BP 77908, 21079 Dijon Cedex, France. ${ }^{15}$ CHD Vendée-Hôpital de la Roche-sur-Yon, Service de Réanimation Polyvalente Les Oudairies, 85925 La Roche-Sur-Yon Cedex 09, France. ${ }^{16}$ Hôpital Raymond Poincaré, APHP, Service de Médecine intensive Réanimation, 104 Boulevard Raymond Poincaré, 92380 Garches, France. ${ }^{17}$ Centre hospitalier de Montauban, service de réanimation polyvalente, 100 rue Léon Cladel, BP 765, 82013 Montauban Cedex, France. ${ }^{18} \mathrm{CH}$ d'Angoulême Service de Réanimation Polyvalente, Rond-Point de Girac CS, 55015 Saint-Michel, 16959 Angoulême Cedex 9, France.

\section{Acknowledgements}

Clinical Research in Intensive Care Sepsis Group (CRICS-TRIGGERSEP): Charlotte Salmon-Gandonniere, MD, PhD, Stephan Ehrmann, MD, PhD, Emmanuelle Mercier, MD, PhD, Julien Grouille, MD, Pierre-François Dequin, MD, PhD, Walid Darwiche, MD, Denis Garot, MD, Marlène Morisseau, MD, Laetitia Bodet Contentin, MD, PhD, Francis Schneider MD,PHD, Vincent Castelain, MD, PhD, Max Guillot, MD, PhD, Vivien Danielo, MD, Jean Etienne Herbrecht, MD, Quentin Maestraggi, MD, Marie Line Harlay, MD, Baptiste Michard, MD, Maleka Schenck, MD, Florence Fagot Gandet, MD, Guillaume Morel, MD, Vincent Souday, MD, Marc Pierrot, MD, Nicolas Lerolle, MD, PhD, Satar Morttaza, MD, Raphaël Clere-Jehl, MD, Hamid Merdji, MD ,Ferhat Meziani, MD, PhD, Laurent Papazian, MD, PhD, Jean Marie Forel, MD, Sami Hraiech, MD, Mélanie Adda MD, Karima Baraka, MD, Florence Daviet, MD, Jo-Anna Tirolien, MD, Gaëtan Plantefeve, MD, Olivier Lesieur, MD, Maxime Leloup, MD, Jean Reignier, MD, PhD, Charlotte Garret, MD, Anthony Lemeur, MD, Isabelle Vinatier, MD, David Schnell, MD, Nicolas Bercault, MD, Dalila Benzekri-Lefevre, MD, Grégoire Muller, MD, Anne Bretagnol, MD, Armelle Mathonnet, MD, Marie Skarzynski, MD, Isabelle Runge, MD, François Barbier, MD, PhD, Sophie Jacquier, MD.

\section{Compliance with ethical standards}

\section{Conflicts of interest}

The authors declare that they have no conflicts of interest in relation to this study.

\section{Publisher's Note}

Springer Nature remains neutral with regard to jurisdictional claims in published maps and institutional affiliations.

Received: 19 September 2019 Accepted: 5 December 2019 Published online: 7 January 2020

\section{References}

1. Goldstein RA, Rohatgi PK, Bergofsky EH et al (1990) Clinical role of bronchoalveolar lavage in adults with pulmonary disease. Am Rev Respir Dis 142:481-486

2. Du Rand IA, Blaikley J, Booton R, British Thoracic Society Bronchoscopy Guideline Group et al (2013) British Thoracic Society guideline for diagnostic flexible bronchoscopy in adults: accredited by NICE. Thorax 68(Suppl 1):i1-i44

3. Albertini RE, Harrell JH, Kurihara N, Moser KM (1974) Arterial hypoxemia induced by fiberoptic bronchoscopy. JAMA 230:1666-1667

4. Guerra LF, Baughman RP (1990) Use of bronchoalveolar lavage to diagnose bacterial pneumonia in mechanically ventilated patients. Crit Care Med 18:169-173

5. Hertz MI, Woodward ME, Gross CR, Swart M, Marcy TW, Bitterman PB (1991) Safety of bronchoalveolar lavage in the critically ill, mechanically ventilated patient. Crit Care Med 19:1526-1532 
6. Steinberg KP, Mitchell DR, Maunder RJ, Milberg JA, Whitcomb ME, Hudson LD (1993) Safety of bronchoalveolar lavage in patients with adult respiratory distress syndrome. Am Rev Respir Dis 148:556-561

7. Baumann HJ, Klose H, Simon M, Ghadban T, Braune SA, Hennigs JK, Kluge S (2011) Fiber optic bronchoscopy in patients with acute hypoxemic respiratory failure requiring noninvasive ventilation - a feasibility study. Crit Care 15:R179

8. Cracco C, Fartoukh M, Prodanovic H et al (2013) Safety of performing fiberoptic bronchoscopy in critically ill hypoxemic patients with acute respiratory failure. Intensive Care Med 39:45-52

9. Schnabel RM, van der Velden K, Osinski A, Rohde G, Roekaerts PM, Bergmans DC (2015) Clinical course and complications following diagnostic bronchoalveolar lavage in critically ill mechanically ventilated patients. BMC Pulm Med 15:107

10. Costa ADS Jr, Scordamaglio PR, Suzuki I, Palomino ALM, Jacomelli M (2018) Indications, clinical outcomes and complications of 1949 flexible bronchoscopies. Einstein (Sao Paulo) 16:eAO4380

11. Al-Qadi MO, Cartin-Ceba R, Kashyap R, Kaur S, Peters SG (2018) The diagnostic yield, safety, and impact of flexible bronchoscopy in non-HIV immunocompromised critically ill patients in the intensive care unit. Lung 196:729-736

12. Azoulay E, Mokart D, Lambert J et al (2010) Diagnostic strategy for hematology and oncology patients with acute respiratory failure: randomized controlled trial. Am J Respir Crit Care Med 182:1038-1046

13. Le Gall JR, Lemeshow S, Saulnier F (1993) A new Simplified Acute Physiology Score (SAPS II) based on a European/North American multicenter study. JAMA 270:2957-2963

14. AARC clinical practice guideline (1993) In-vitro pH and blood gas analysis and hemoximetry. American Association for Respiratory Care. Respir Care 38:505-510

15. Agresti A (2010) Analysis of ordinal categorical data, 2nd edn. Wiley, New York

16. Antonelli M, Conti G, Rocco M et al (2002) Noninvasive positive-pressure ventilation vs. conventional oxygen supplementation in hypoxemic patients undergoing diagnostic bronchoscopy. Chest 121:1149-1154

17. Maitre B, Jaber S, Maggiore SM et al (2000) Continuous positive airway pressure during fiberoptic bronchoscopy in hypoxemic patients. A randomized double-blind study using a new device. Am J Respir Crit Care Med 162(3 Pt 1):1063-1067

18. Simon M, Braune S, Frings D et al (2014) High-flow nasal cannula oxygen versus non-invasive ventilation in patients with acute hypoxaemic respiratory failure undergoing flexible bronchoscopy-a prospective randomised trial. Crit Care 18:712

19. Frat J-P, Thille AW, Mercat A et al (2015) High-flow oxygen through nasal cannula in acute hypoxemic respiratory failure. N Engl J Med 372:2185-2196

20. Kim EJ, Jung CY, Kim KC (2018) Effectiveness and safety of highflow nasal cannula oxygen delivery during bronchoalveolar lavage in acute respiratory failure patients. Tuberc Respir Dis 81:319-329

21. La Combe B, Messika J, Labbé V et al (2016) High-flow nasal oxygen for bronchoalveolar lavage in acute respiratory failure patients. Eur Respir J 47:1283-1286
22. Service JA, Bain JS, Gardner CP, MCNarry AF (2019) Prospective experience of high-flow nasal oxygen during bronchoscopy in 182 patients: a feasibility study. J Bronchology Interv Pulmonol 26:66-70

23. Bauer PR, Chevret S, Yadav H, Efraim Investigators and The Nine-I Study Group et al (2019) Diagnosis and outcome of acute respiratory failure in immunocompromised patients after bronchoscopy. Eur Respir J 54:1802442

24. Bone RC, Aviles A, Faber LP (1982) Guidelines for competency and training in fiberoptic bronchoscopy. Section on bronchoscopy, American College of Chest Physicians. Chest 81:739

25. Febvre M, Trosini-Desert V, Atassi K, Endoscopy Working Group of the French Society of Pulmonary Medicine et al (2007) Diagnostic flexible bronchoscopy. recommendations of the endoscopy working group of the French Society of Pulmonary Medicine. Rev Mal Respir 24:1363-1392

26. Libby LJ, Gelbman BD, Altorki NK, Christos PJ, Libby DM (2014) Surgical lung biopsy in adult respiratory distress syndrome: a meta-analysis. Ann Thorac Surg 98:1254-1260

27. Wang JY, Chang YL, Lee LN, Chen JH, Tang JL, Yang PC, Lee YC (2004) Diffuse pulmonary infiltrates after bone marrow transplantation: the role of open lung biopsy. Ann Thorac Surg 78:267-272

28. Esposito S, Mencacci A, Cenci E, Camilloni B, Silvestri E, Principi N (2019) Multiplex platforms for the identification of respiratory pathogens: are they useful in pediatric clinical practice? Front Cell Infect Microbiol 9:196

29. Clavel M, Barraud O, Moucadel V, Meynier F, Karam E, Ploy MC, François B, VALIBI Study Group (2016) Molecular quantification of bacteria from respiratory samples in patients with suspected ventilator-associated pneumonia. Clin Microbiol Infect 22:812-812

30. Lacroix M, Barraud O, Clavel M et al (2015) Rapid quantification of Staphylococcus aureus from endotracheal aspirates of ventilatedpatients: a proof-of-concept study. Diagn Microbiol Infect Dis 83:117-120

31. Peña E, Souza CA, Escuissato DL, Gomes MM, Allan D, Tay J, Dennie CJ (2014) Noninfectious pulmonary complications after hematopoietic stem cell transplantation: practical approach to imaging diagnosis. Radiographics 34:663-683

32. Tanaka N, Kunihiro Y, Yanagawa N (2018) Infection in immunocompromised hosts: imaging. J Thorac Imaging 33:306-321

33. Amann A, Costello Bde L, Miekisch W et al (2014) The human volatilome: volatile organic compounds (VOCs) in exhaled breath, skin emanations, urine, feces and saliva. J Breath Res 8:034001

34. Kalil AC, Metersky ML, Klompas M et al (2016) Management of adults with hospital-acquired and ventilator-associated pneumonia: 2016 clinical practice guidelines by the infectious diseases society of America and the American Thoracic Society. Clin Infect Dis 63:e61-e111

35. Torres A, Niederman MS, Chastre J (2017) The International ERS/ESICM/ ESCMID/ALAT guidelines for the management of hospital-acquired pneumonia and ventilator-associated pneumonia: guidelines for the management of hospital-acquired pneumonia (HAP)/ventilatorassociated pneumonia (VAP) of the European Respiratory Society (ERS), European Society of Intensive Care Medicine (ESICM), European Society of Clinical Microbiology and Infectious Diseases (ESCMID) and Asociación Latinoamericana del Tórax (ALAT). Eur Respir J 50:1700582 